\title{
Fórmula (-1): desenvolvendo objetos digitais de aprendizagem e estratégias para a aprendizagem das operações com números positivos e negativos
}

\author{
Anuar Daian de Morais \\ Cristiano Lopes Lima \\ Marcus Vinicius de Azevedo Basso \\ \{anuar_com_u@yahoo.com.br, clopeslima@gmail.com,mbasso@ufrgs.br\} \\ Instituto de Matemática - Universidade Federal do Rio Grande do Sul
}

\section{Resumo}

Nesse artigo apresentamos uma proposta de Objeto Digital para Aprendizagem (ODA) para promover a aprendizagem de operações com números inteiros sob a perspectiva da teoria dos Campos Conceituais de Gerard Vergnaud. Para auxiliar na construção do ODA, foi aplicado um conjunto de dezoito situações problemas para 25 crianças da $6^{a}$ série do Ensino Fundamental do Colégio de Aplicação de Porto Alegre. A análise dos resultados obtidos serviu como subsídio para a implementação de algumas modificações no ODA e que serão descritas neste trabalho. De caráter experimental, esse trabalho faz parte de uma pesquisa de mestrado tendo como objetivo desenvolver um conjunto de objetos virtuais para aprendizagem das estruturas Aditivas e Multiplicativas sob a perspectiva dos Campos Conceituais de Vergnaud.

Palavras-chave: objetos digitais de aprendizagem, matemática, operações com inteiros

\begin{abstract}
This article to present a propose of a Learning Digital Object (LDO) that promote the learning of additive structures trhough Vergnaud's Conceptual Fields. To help during the LVO construction, it was applied a set of eighteen problem-situation with 25 sixth grade students from Colégio de Aplicação at Porto Alegre. The analysis of the results we got it helped as a foundation to implementation of some changins at the LDO and will be presented at this article. This work has a experimental characteristical and belongs to a master's reserach with the objective to develop a set of additive and multiplicative learning virtual objects trough Vergnaud's Conceptual Fields perspective. Furthermore, it will be developed a diactical propose for the use of this objects
\end{abstract}

Keywords: digital learning objects, mathematics, integer operations

\section{Introdução}

Desenvolver alternativas para o ensino e aprendizagem das operações com números positivos e negativos é fundamental, já que estudantes de diferentes níveis do ensino básico apresentam dificuldades para realizar tais operações. Porém, tal dificuldade não é gratuita visto que a humanidade levou mais de 1000 anos para aceitar e compreender os números negativos. No entanto, o ensino desse conteúdo está repleto de procedimentos mecânicos que limitam a própria compreensão do conceito de número, bem como o desenvolvimento do raciocínio aditivo dos nossos estudantes. De acordo com os Parâmetros Curriculares Nacionais "o ensino dos números inteiros podem surgir como ampliação do campo aditivo, pela análise de situações em que esses números estejam presentes" (p. 66). Partindo dessa premissa, desenvolvemos o objeto digital Fórmula (-1). Tal objeto é um jogo que procura promover a aprendizagem das operações com números positivos e negativos. Para desenvolver o ODA Fórmula (-1), utilizamos como suporte teórico a teoria de Campos Conceituais de Vergnaud. Segundo este autor, "Campo Conceitual é definido como um conjunto de problemas e situações cujo tratamento requer conceitos, procedimentos e representações de tipos diferentes 
intimamente relacionados" (1983b apud MOREIRA p.127).

Diante deste desafio surge a pergunta:

Como um objeto digital de aprendizagem pode promover o desenvolvimento do raciocínio aditivo envolvendo operações com números positivos e negativos sob a perspectiva dos Campos Conceituais de Vergnaud?

\section{Fundamentação Teórica}

O Campo Aditivo é definido como um conjunto de problemas e situações que envolvem soma ou subtração na sua resolução. Embora sejam operações distintas, ambas referem-se à relação parte-todo e é esse invariante conceitual que relaciona soma/subtração à uma mesma estrutura de raciocínio, o raciocínio Aditivo. Portanto, soma/subtração são definidas como operações irmãs, já que podemos resolver o mesmo problema utilizando uma ou outra. Abaixo apresentamos três variações deste problema.

\section{Transformação Direta}

Transformação Indireta

Comparação entre medidas

1) Nilce tinha sete pares de 2) Nilce ganhou quatro pares 3) Nilce tinha sete pares de brincos. No seu aniversário de brincos no seu aniversário brincos. Após seu aniversário ganhou mais quatro pares. e ficou com um total de 11 ficou com 11 pares. Quantos Quantos pares ela tem? pares. Quantos pares ela pares ela ganhou? possuía antes?
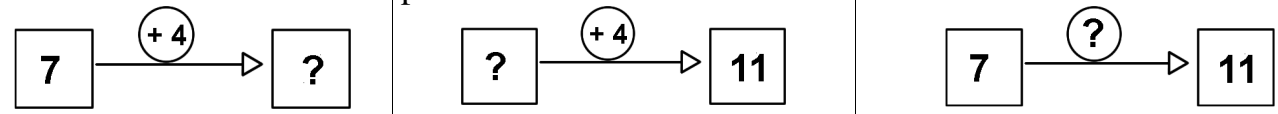

Pelas situações apresentadas, podemos observar que a operação utilizada na resolução depende do "lugar" onde a incógnita está localizada. No entanto, as três variações do problema se referem à mesma relação parte-todo.

No livro "El niño, las matemáticas y la realidad: problemas de la ensenhanza de las matemáticas en la escuela primaria”, Vergnaud apresenta as principais categorias de problemas que envolvem o raciocínio aditivo. $\mathrm{O}$ autor comenta que existem números que expressam a medida de conjuntos de objetos concretos, porém, ao utilizar o raciocínio aditivo para resolver problemas, surgem números que expressam transformações de medidas. Assim, estamos diante de dois tipos diferentes de números: os primeiros são chamados de números naturais e expressam a cardinalidade de conjuntos (portanto não são positivos nem negativos); já os números do segundo tipo são chamados de números inteiros e expressam transformações (ganho ou perda) e, portanto, são dotados dos sinais positivo e negativo.

Abaixo descrevemos as seis categorias de problemas descritas por Vergnaud.

$1^{\mathbf{0}}$ Categoria: São problemas onde duas medidas se compõem para dar lugar a uma medida.

Ex: Osmar tem 6 canecas de vidro e 8 de metal. Quantas canecas têm no total?

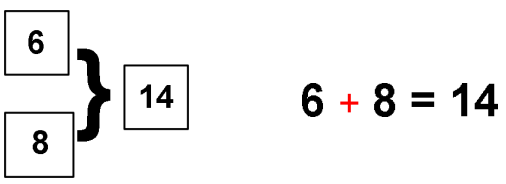

+ É a lei de composição que corresponde à adição de medidas, é decidir sobre a soma de dois números naturais.

$2^{\circ}$ Categoria: São problemas onde uma transformação opera sobre uma medida para dar lugar a outra medida.

Exemplo A: Nilce tem 7 moedas de 1 real antes de começar a jogar. Ganhou 4 moedas, agora tem? 
$+\quad$ É a lei de composição que corresponde $7 \stackrel{+4}{\longrightarrow} 11 \quad 7+(+4)=11$ à aplicação de uma transformação sobre uma medida; é realizar a adição de um número natural (7) e de um número relativo (+4).

Exemplo B: Osmar tem 7 moedas de 1 real antes de começar a jogar. Perdeu 4 moedas, agora tem?

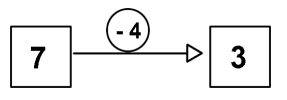

$$
7+(-4)=3
$$

$3^{\circ}$ Categoria: São problemas onde uma relação une duas medidas.

Exemplo: Osmar tem 8 moedas. Nilce tem 5 moedas a menos que Osmar. Quantas moedas tem Nilce?

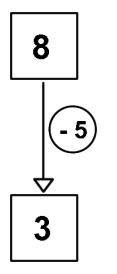

$$
8+(-5)=3
$$

Vergnaud lembra que este exemplo é uma relação estática e não uma transformação.

$4^{\circ}$ Categoria: São problemas onde duas transformações se compõem para dar lugar a uma transformação.

Exemplo: Osmar ganhou 6 canecas, mas em seguida perdeu 9. No total perdeu?

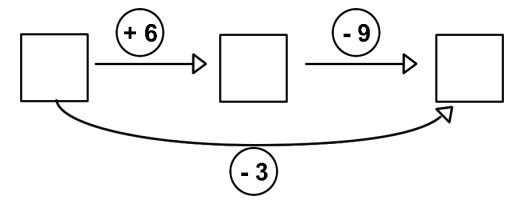

$$
(+6)+(-9)=(-3)
$$

$5^{\circ}$ Categoria: São problemas onde uma transformação opera sobre um estado relativo (uma relação) para dar lugar a um estado relativo.

Exemplo: Osmar devia 6 moedas a Nilce. Devolveu-lhe quatro. Quanto ficou devendo?

$$
(-6)+(+4)=(-2)
$$

$6^{\circ}$ Categoria: São problemas onde dois estados relativos (relações) se compõem para dar lugar a um estado relativo.

Exemplo: Nilce deve seis moedas a Osmar, porém Osmar deve quatro moedas à Nilce. $\mathrm{Na}$ realidade, quanto Nilce deve a Osmar?

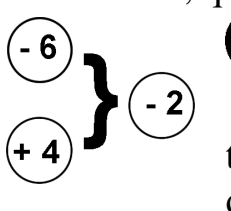

$(-6)+(+4)=(-2)$

* Esta lei de transformação corresponde à operação de uma transformação de um estado relativo a outro. Rigorosamente falando, é diferente da adição das transformações que acabamos de ver na quarta categoria, tanto num estado relativo como numa transformação são representados por números relativos. Esta lei de composição representa uma adição de estados relativos. Por essa razão não precisa utilizar símbolos diferentes. 
NUNES (2001, pg.45) sintetiza em seu livros algumas das contribuições de Piaget (esquemas de ação) e Vigotsky (instrumento simbólico). Segundo essa autora, no desenvolvimento do raciocínio aditivo a criança utiliza os esquemas de ação de juntar e tirar ao resolver problemas que necessitam de soma ou subtração na sua resolução. Esses esquemas permitem que as crianças resolvam os problemas de forma prática e podem ser observados a partir de uma afirmação, pequenos movimentos com dedos ou olhos e etc. Por outro lado, tais esquemas de ação precisam estar coordenados com o sistema simbólico, ou seja, a utilização de símbolos como ferramenta para registrar e quantificar as operações realizadas na prática, o instrumento simbólico. Uma criança que se encontra no início do ensino fundamental, já realizou várias coordenações desse tipo, pois consegue coordenar os esquemas de ação com o sistema decimal, com a utilização dos algoritmos, tanto no campo aditivo como no multiplicativo. No entanto, ao realizar operações com números inteiros, ela deve coordenar esses novos símbolos com o seu sistema de ação. Portanto, estenderá o raciocínio aditivo, bem como sua noção matemática de número.

\section{O Jogo Fórmula (-1)}

O objeto digital de aprendizagem Fórmula (-1) é um jogo que visa promover o desenvolvimento do raciocínio aditivo, através da ampliação e construção de novos significados para as operações com números positivos e negativos. Nele, duas lesmas disputam uma corrida tendo como referência uma reta numérica, como mostra a figura 1 a seguir.

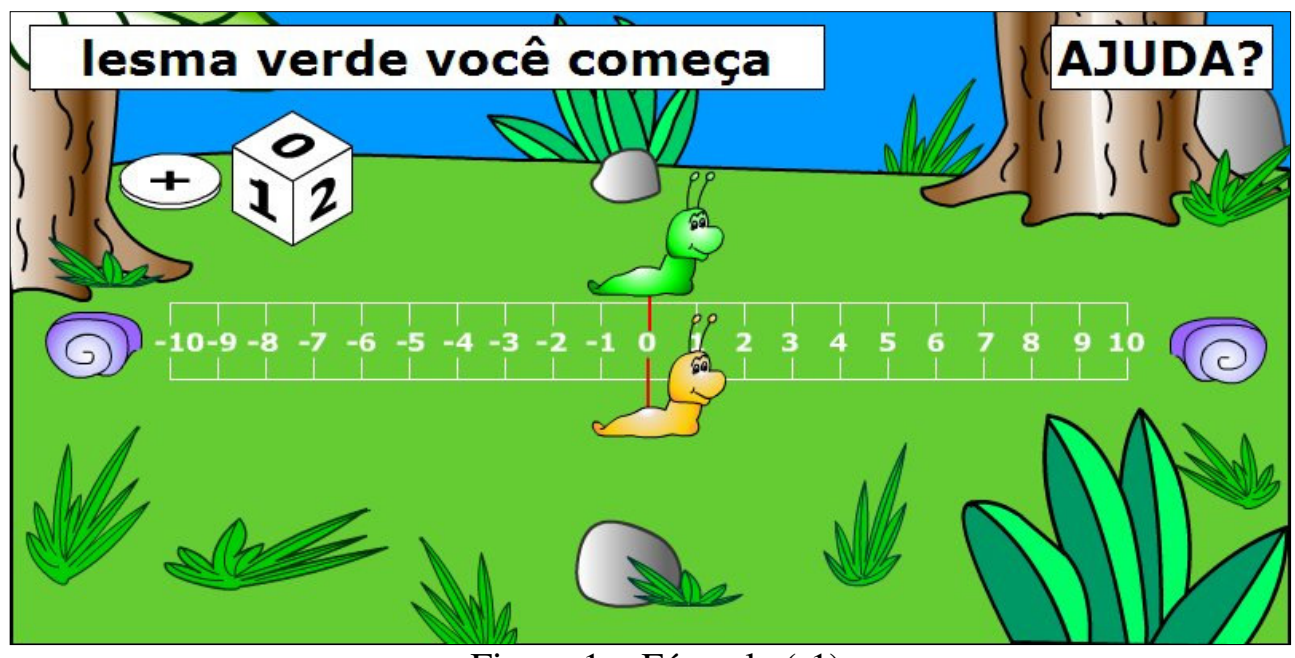

Figura 1 - Fórmula (-1)

Portanto, para determinar o deslocamento das lesmas (e vencer o jogo) os jogadores terão que realizar operações com números positivos e negativos, já que estão inseridas num sistema referencial. Por exemplo:

Ao clicar no dado será sorteado um número:

Exemplo 1:

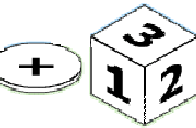

Exemplo 2:
Com isso, a lesma deverá deslizar 3 posições para direita (sentido positivo). Se a lesma estiver na posição +1 podemos representar seu deslocamento pela expressão: $(+1)+(+3)=(+4)$ (esquema de ação de juntar)

Já neste caso, deve deslizar 3 posições para a esquerda (sentido negativo). Se a lesma estiver na posição +1 podemos representar seu deslocamento pela expressão: $(+1)+(-3)=(-2)$ (esquema de ação de retirar) 
Supomos que a partir dessa interação com o ODA, as crianças poderão estabelecer relações e generalizações a respeito das operações envolvidas, já que ao utilizar esquemas de ação, conseguirão resolver problemas de modo prático, ampliando, assim, seus sistemas de ações para resolver tais problemas. Cabe ao educador(a) fomentar a coordenação entre os sistemas de ação c e os sistemas simbólicos, via uma proposta didática que contribua para esta sistematização. Segundo Piaget, ao estudar o desenvolvimento das crianças escreve, "que é através da coordenação dos Sistemas de Ação e Sistemas Simbólicos que as crianças desenvolvem o raciocínio Aditivo e Multiplicativo". (2001 apud NUNES)

Consideramos que as situações-problemas apresentadas no objeto digital de aprendizagem pertencem à quinta e sexta categorias do Campo Aditivo, tendo em vista que os deslocamentos das lesmas são transformações sofridas pelas medidas de distâncias e a posição das lesmas são estados relativos de um sistema referencial.

A segunda fase do Fórmula (-1) prioriza a representação simbólica, pois, além da utilização dos esquemas de ação, torna-se necessário a utilização do sistema simbólico para realizar o deslocamento das lemas, como indica a figura abaixo.

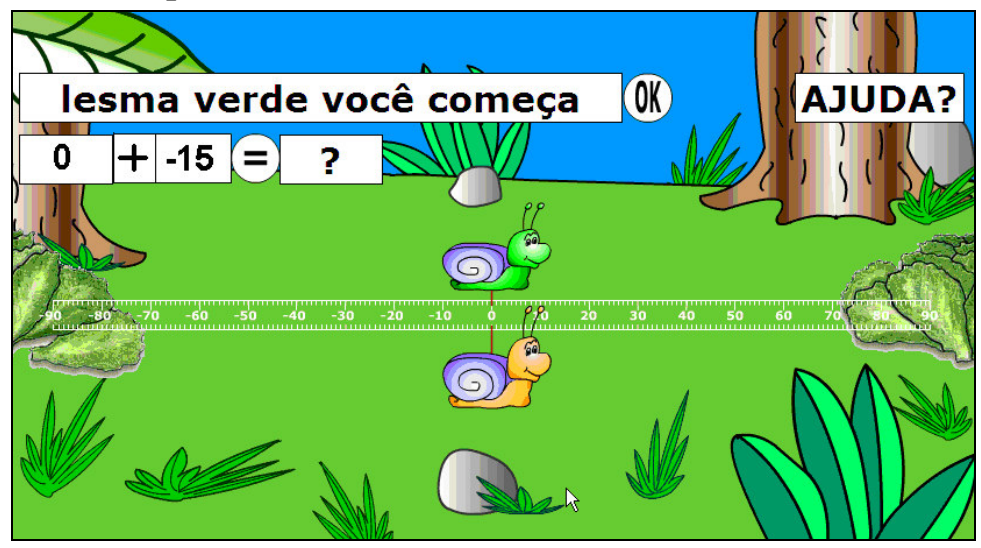

Neste exemplo, a lesma verde está na posição inicial (zero) e deverá deslizar 15 posições para esquerda (sentido negativo).

Figura 2 - Fórmula (-1) - segunda fase

Logo, o ODA pode servir como mais uma alternativa para fomentar a coordenação entre Sistemas de Ação e Simbólicos e, assim, estender o raciocínio aditivo para operações que envolvem operações com números negativos.

\section{Dados - aplicação de um Pré-teste}

Como já nos referimos anteriormente, este trabalho é parte de uma pesquisa de mestrado em ensino de Matemática que tem como objetivo investigar como um objeto digital para a aprendizagem pode promover experiências que contribuam para o desenvolvimento do raciocínio Aditivo e Multiplicativo em situações envolvendo operações com números positivos e negativos. Também está previsto nessa pesquisa a criação de uma proposta didática para utilização dos ODAs, bem como a aplicação prática desta proposta no Ensino Fundamental.

A seguir, apresentamos um conjunto de dezoito situações problemas que foi aplicado em 25 crianças da $6^{\text {a }}$ série do Ensino Fundamental do Colégio de Aplicação de Porto Alegre. Tais perguntas fazem parte de um pré-teste que tinha como objetivo coletar dados que permitissem identificar as estratégias e representações utilizadas pelos alunos ao resolver problemas do campo aditivo e realizar modificações no ODA. Cada aluno recebeu uma folha com problemas para serem resolvidos e lhes foi solicitado que apresentassem uma justificativa para cada resposta encontrada, seja via desenho, explicação escrita ou conta. 
"Na figura abaixo temos Flávio, um atleta que pratica caminhada, corrida e ciclismo. Nesta avenida, Flávio movimenta-se em linha reta em apenas dois sentidos: para direita $(\rightarrow)$ ou para esquerda $(\leftarrow)$. Na pista em que pratica exercícios fez marcações em relação ao prédio em que mora (posição 0)."

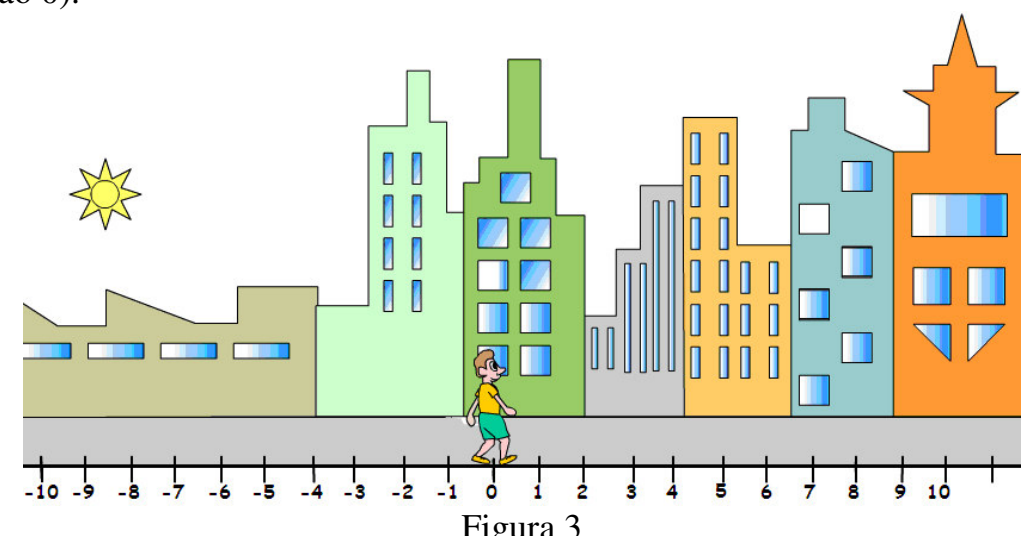

Figura 3

1. Partindo da posição +3 Flávio movimentase 5 metros para direita. Qual será sua posição?

2. Partindo da posição -2 o atleta anda 8 metros para esquerda. Qual será sua posição?

3. Partindo da posição -7 Flávio movimentase 10 metros para direita. Qual será sua posição?

4. Partindo da posição +6 o atleta anda 11 metros para esquerda. Qual será sua posição?

5. Agora Flávio caminhou 12 metros para direita e encontrou uma amiga que estava na posição +5 . Qual foi sua posição de partida?

6. Tal atleta partiu da posição 10 e parou na posição -7 , qual foi o deslocamento realizado por ele?

7. Partindo da posição 0 , nosso atleta anda 4 metros para esquerda e pára ao encontrar um amigo. Logo em seguida anda 6 metros para esquerda. Qual será sua posição?

8. Qual será a posição do atleta após movimentar-se 4 metros para direita e 5 metros para esquerda, sabendo que partiu da posição 0? Qual foi a distância percorrida por ele?

9. Partindo da posição 0 Flávio anda 8 metros para esquerda e pára ao encontrar um amigo. Logo em seguida anda 6 metros para direita.

a) Qual será sua posição?

b) Qual foi a distância percorrida por ele?

10.Partindo da posição -7 o atleta movimentase 10 metros para direita. Qual será sua posição?
11.Ao se locomover 12 metros para esquerda o andarilho, Flávio, tropeça numa pedra mas continua o trajeto por mais 6 metros e pára na posição -8.

a) A pedra estava em qual posição?

b) Qual foi seu ponto de Partida?

12.Após andar 13 metros para esquerda Flávio lembrou que deveria comprar frutas para fazer um suco. Assim, ele pára e anda 7 metros para direita até uma fruteira que fica na posição +2 . Qual foi era sua posição:

a) ao lembrar-se das frutas?

b) da partida?

c) Qual o total da distância que ele percorreu?

13.Partindo da posição 0 , o atleta anda 4 metros para esquerda e pára ao encontrar um amigo. Logo em seguida anda 6 metros para esquerda. Qual será sua posição?

14. Após fazer seu alongamento ele corre 512 metros para direita. Qual será a sua posição sabendo que partiu da posição -213 .

15.Num outro dia ele correu 635 para esquerda e parou na posição -218. Qual foi seu ponto de partida?

16. Partindo da posição $+2,5$ metros, Flávio caminha 6,7 metros para direita. Qual é sua posição?

17. Flávio caminha 6,7 metros para direita e pára na posição $+5,8$. Qual foi sua posição de partida?

18. Flávio estava muito cansado e resolveu voltar para casa, estava na posição -20 , após caminhar 15,8 metros para direita quanto falta para chegar em casa? 


\section{Análise dos Resultados:}

Vamos analisar os resultados formando 5 grupos de problemas com diferentes níveis de dificuldades. Os grupos 1 e 2 representam as situações que permitem uma compreensão inicial do raciocínio aditivo que envolve operações com números inteiros e que teriam maior influência nas modificações no ODA Fórmula (-1). Já os problemas dos grupos 3, 4 e 5 envolvem situações mais complexas, pois envolvem operações com "números grandes", racionais ou que contenham transformações sucessivas.

GRUPO 1 - Problemas que envolvem resolução na forma direta, ou seja, a incógnita está localizada na parte final da transformação.

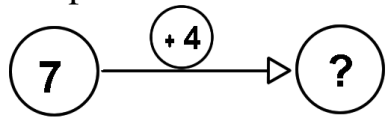

e

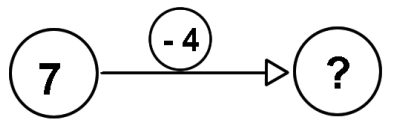

Nos problemas 1 e 2 utiliza-se o esquema de ação de junta. No problema 1 a justificativa geométrica para a operação é: "A resposta final será positiva já que o sujeito movimenta-se para direita ao partir de uma posição positiva (a direita de zero), logo somamos seus deslocamentos para determinar seu deslocamento.” Já no problema 2 a justificativa geométrica é a situação análoga para esquerda: "A resposta final será negativa, pois o sujeito parte de uma posição negativa (à esquerda de zero) $e$ movimenta-se para esquerda".

Os problemas 3 e 4 utilizam o "esquema de tirar" na sua resolução. No problema 3 a justificativa geométrica é: "A resposta final será positiva, pois o sujeito está 7 metros à esquerda de zero (parte negativa) e ao andar 10 metros para direita irá parar 3 metros à direita do zero, logo subtraímos essas distâncias”. Já no problema 4 a justificativa consiste na situação geométrica análoga: "A resposta final será negativa, pois o sujeito está 6 metros à direita de zero (parte positiva da reta) e ao andar 11 metros para esquerda irá parar 5 metros à esquerda do zero, portanto subtraímos essas distâncias".

Neste grupo temos a primeira interpretação para a subtração, pois é realizada através de um operador e possui o significado geométrico de "andar para esquerda".

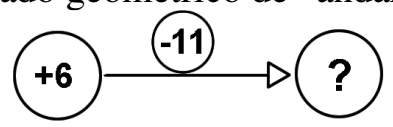

Alunos da $6^{\circ}$ série (25 alunos no total)

\begin{tabular}{|c|c|c|}
\hline Questões & Acertos & $\begin{array}{c}\text { Acertos } \\
\text { (\%) }\end{array}$ \\
\hline $\mathbf{1}$ & 24 & $\mathbf{9 6}$ \\
\hline $\mathbf{2}$ & 18 & $\mathbf{7 2}$ \\
\hline $\mathbf{3}$ & 21 & $\mathbf{8 4}$ \\
\hline $\mathbf{4}$ & 19 & $\mathbf{7 6}$ \\
\hline
\end{tabular}

Podemos observar que os alunos da $6^{\circ}$ série tiveram uma porcentagem alta de acertos nas quatro primeiras questões. Porém, observa-se que o número de acertos nos problemas 2 e 4 é menor, o que corresponde justamente as situações cuja resposta final é negativa.

Por outro lado, observamos que, apesar de resolver corretamente, as crianças se "atrapalham" para explicar ou representar suas contas, visto que é necessário realizar coordenação entre os esquemas de ação - que permitem a resolução correta - com a novidade dos sinais positivos e negativos incorporados ao sistema simbólico. Frequentemente as crianças registram suas respostas da seguinte forma "ele parou na posição 3-", reproduzindo na escrita a forma falada.

GRUPO 2 - Tal grupo é formado por problemas que envolvem resolução na forma inversa, ou seja, a incógnita está localizada na parte inicial da transformação. Por exemplo: 


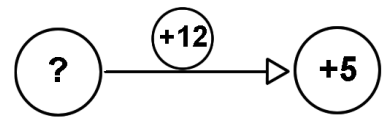

\section{Expressão numérica

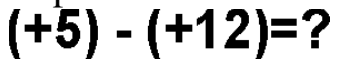

Observe que é apresentada uma interpretação diferente para a subtração, ou seja, como operação inversa da soma, geometricamente apresenta a idéia de "o contrário de andar para direita."

Tal interpretação foi representada nos problemas 5, 8 e 11. Como leitor das idéias desenvolvidas por Piaget, é interessante observar e re-confirmar que o raciocínio inverso é sempre mais difícil para os aprendizes. Examinemos a tabela abaixo.

\begin{tabular}{|c|c|c|c|}
\hline Questões & $A_{\text {Nertos }}$ & Acertos(\%) & N.F. (\%) \\
\hline $\mathbf{5}$ & 16 & $\mathbf{6 4}$ & $\mathbf{4}$ \\
\hline $\mathbf{6}$ & 5 & $\mathbf{2 0}$ & $\mathbf{4}$ \\
\hline $\mathbf{8 a}$ & 13 & $\mathbf{5 2}$ & $\mathbf{1 2}$ \\
\hline $\mathbf{8 6}$ & 21 & $\mathbf{8 4}$ & $\mathbf{1 6}$ \\
\hline $\mathbf{1 1 a}$ & 10 & $\mathbf{4 0}$ & $\mathbf{2 4}$ \\
\hline 11b & 9 & $\mathbf{3 6}$ & $\mathbf{4}$ \\
\hline
\end{tabular}

Podemos observar que a quantidade de acertos diminui consideravelmente. Observe que $84 \%$ daqueles que resolveram a questão $8 \mathrm{~b}$, a responderam corretamente. Para respondê-la bastava somar as distâncias apresentadas no enunciado do problema.

No entanto, nas questões onde a incógnita era a posição de partida $(5,8$ a e 11$)$ apresentaram um média de acertos de $48 \%$.. É importante registrar que as questões mais difíceis do pré-teste eram as questões 8a e 11 pois apresentam a intersecção entre os grupos 2 e 3. Porém, a surpresa deste grupo foi a questão 6 cujo objetivo era definir a representação do deslocamento para esquerda como negativo, definindo assim, uma das interpretações da subtração.

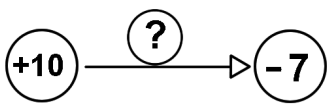

No entanto, a resposta mais apresentada foi +17 , ou seja, as crianças não diferenciaram que o significado de deslocar-se 17 metros para esquerda é diferente de deslocar-se 17 metros para direita.

GRUPO 3 - Tal grupo é formado pelos problemas (7, 9 e 12) que apresentam transformações sucessivas e compostas. Como exemplo, apresentamos o esquema de flechas do problema 7.

Partindo da posição 0 , nosso atleta anda 4 metros para esquerda e pára ao encontrar um amigo. Logo em seguida anda 6 metros para esquerda. Qual será sua posição?

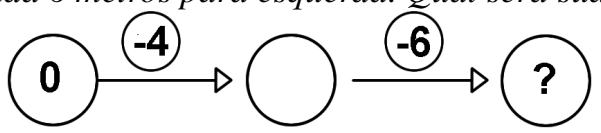

\begin{tabular}{|c|c|c|}
\hline Questões & Acertos & $\begin{array}{c}\text { Acertos } \\
\text { (\%) }\end{array}$ \\
\hline $\mathbf{7}$ & 12 & $\mathbf{4 8}$ \\
\hline $\mathbf{9 a}$ & 18 & $\mathbf{7 2}$ \\
\hline $\mathbf{9 b}$ & 19 & $\mathbf{7 6}$ \\
\hline $\mathbf{1 0}$ & 17 & $\mathbf{6 8}$ \\
\hline $\mathbf{1 2 a}$ & 7 & $\mathbf{2 8}$ \\
\hline $\mathbf{1 2} \mathbf{b}$ & 6 & $\mathbf{2 4}$ \\
\hline $\mathbf{1 2 c}$ & 6 & $\mathbf{2 4}$ \\
\hline
\end{tabular}

Podemos observar que a maior porcentagem de acertos está concentrada nas questões cuja posição inicial é o zero, no entanto são essa média de acertos é inferior aos acertos do grupo 1 assemelhando-se aos resultados do grupo 2. Já a porcentagem de acerto diminui consideravelmente naquelas questões que envolvem naquelas que envolvem transformações sucessivas sendo que a posição inicial é diferente de zero.

Foram nessas questões e nas do grupo 4 que as crianças tinham maior dificuldade de entender sobre aquilo que estava sendo perguntado.

GRUPO 4 - Problemas que Envolvem Operações com Números Grandes

Este grupo é formado pelos problemas 14 e 15. Tais problemas apresentam um grau de dificuldade maior pois envolvem números que excedem as distâncias apresentadas na reta numérica do pré-teste. Minha hipótese é que para resolvê-los a 
criança deverá ter coordenado as relações estabelecidas ao utilizar os esquemas de ações (andar direita/esquerda) e simbólico (diferenciação entre deslocamento, distância e posição relativa) nos problemas do grupo 1 ou representando-os numa reta numérica com escala maior.

\begin{tabular}{|c|c|c|c|}
\hline Questóes & Acertos & Acertos\% & M.F. \% \\
\hline 14 & 8 & $\mathbf{3 2}$ & $\mathbf{3 6}$ \\
\hline $\mathbf{1 5}$ & 6 & $\mathbf{2 4}$ & $\mathbf{4 4}$ \\
\hline
\end{tabular}

Podemos observar que $36 \%$ das crianças não fizeram o problema 14 e, daqueles que o fizeram, apenas $32 \%$ o responderam corretamente.

Já no problema 15, 44\% não fizeram e apenas $24 \%$ acertaram sua resposta. Tal resultado confirma minha hipótese? Ainda não é possível fazer tal afirmação, pois temos dúvidas se os alunos não conseguiram realizá-lo por falta de tempo. No entanto, podemos concluir que os alunos da $6^{\circ}$ série não conseguem resolver problemas que envolvam números inteiros elevados. Para além disso, levantamos uma questão adicional: será que a dificuldade de representação simbólica apresentada nas questões do GRUPO 1 contribuem para o insucesso desses estudantes?

GRUPO 5 - Problemas que Envolvem Operações com Números Racionais

Os problemas de 16 a 18 integram este grupo pois apresentam situações que necessitam operações com números racionais negativos e positivos. Tais problemas apresentam um grau de dificuldade maior, tendo em vista que é necessária a coordenação entre o sistema posicional decimal, bem como a representação dos números racionais na reta numérica. Além disso, a relação de ordem torna-se fundamental, já que é sutil determinar se -0,5 é maior ou menor que -0,4.

\begin{tabular}{|c|c|c|}
\hline Questố & Acstos & Acertos $/ 9$ \\
\hline $\mathbf{6}$ & 0 & 0 \\
\hline 7 & 0 & 0 \\
\hline $\mathbf{8}$ & 0 & 0 \\
\hline
\end{tabular}

Nas situações-problemas 16 e $1740 \%$ dos alunos não resolveram e $36 \%$ dos alunos não fizeram o problema 18. Entre aqueles alunos que resolveram a grande maioria errou as operações que envolviam números decimais.

Outras crianças realizaram a soma ou subtração corretamente. No entanto, erravam o sinal da resposta final.

Quadro geral da porcentagem de acertos do pré-teste da $6^{\circ}$ série.

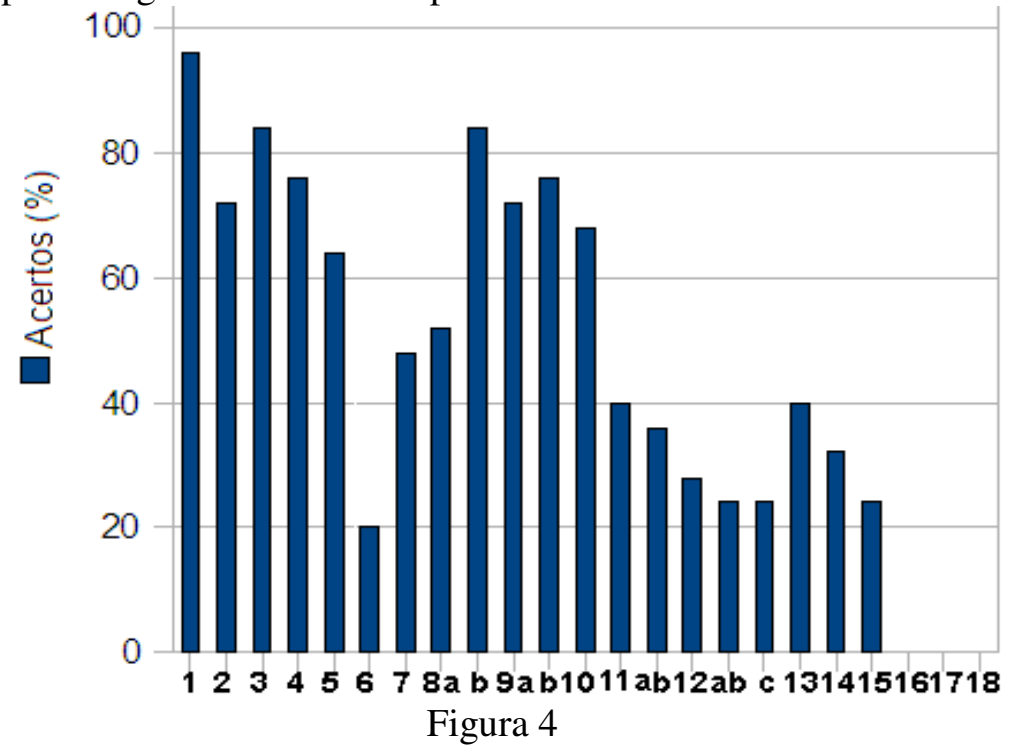




\section{Conclusões}

Voltamos à pergunta apresentada no início deste artigo: Como um objeto digital de aprendizagem pode promover o desenvolvimento do raciocínio aditivo envolvendo operações com números positivos e negativos sob a perspectiva dos Campos Conceituais de Vergnaud?

Ao analisar os resultados apresentados pelas crianças nos problemas dos grupos 1 e 2, ficou claro que as crianças conseguem resolver problemas ao utilizar seus esquemas de ação de forma prática. No entanto, não conseguem representá-los via escrita. Esse resultado confirma a falta de coordenação entre os sistemas de ação e simbólicos apresentada nas pesquisas de NUNES e VERGNAUD. No entanto, a oportunidade de testar e observar tal fenômeno, deixou evidente que era necessário realizar algumas modificações no objeto digital para a aprendizagem Fórmula (-1) considerando que sua principal contribuição seria "sugerir" novas formas para representar os cálculos realizados pelos alunos. Com certeza, a facilidade apresentada pela interação que um jogo virtual, contribui para o desenvolvimento dos esquemas de ação das crianças. No entanto, o jogo Fórmula (-1) pode oferecer melhores representações simbólicas e que promovam a coordenação dos sistemas envolvidos. Dessa forma, nossa idéia adicional foi acrescentar uma fase intermediária que utilize o modelo de representação por flechas (figura 5).

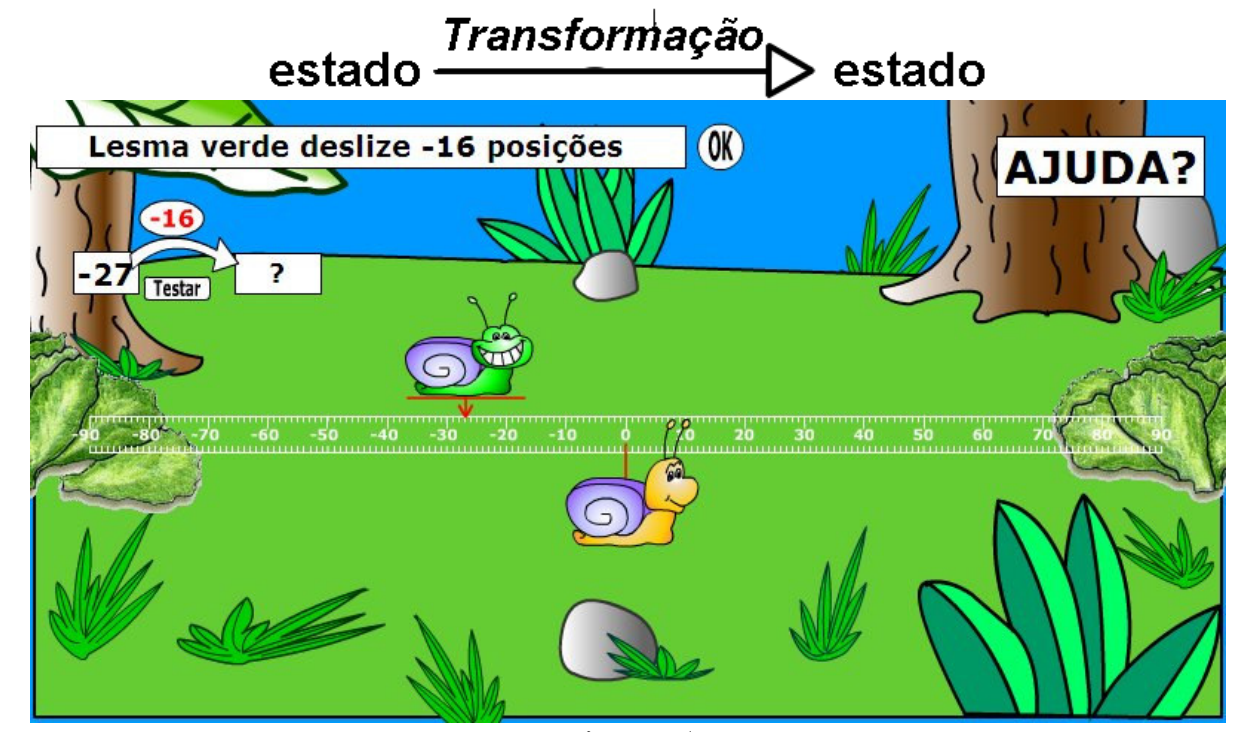

Figura 5

Segundo Vergnaud, este modelo representa muito bem as relações ternárias, visto que deixa explícita a transformação sofrida pelos elementos.

Veja alguns exemplos:

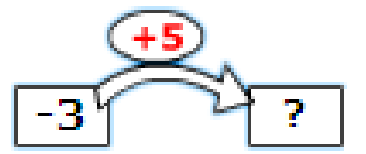

Significa que a lesma está na posição -3 e deve deslizar 5 posições para direita. (sentido positivo).

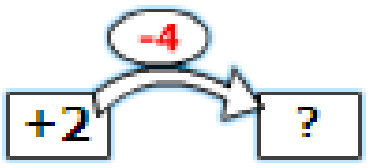

Significa que a lesma está na posição +2 e deve deslizar 4 posições para esquerda. (sentido positivo).

Mesmo que este esquema seja amplamente utilizado por Vergnaud e tenha nos ajudado a entender a teoria dos Campos Conceituais, não havíamos considerado, 
inicialmente, sua a importância na utilização do ODA aqui descrito. Tal necessidade surgiu em decorrência da aplicação do pré-teste. Embora a idéia inicial fosse a de utilizar o Fórmula (-1) apenas para apresentar um conjunto de situações que envolviam operações com números positivos e negativos, a sistematização das operações caberia ao professor mediante a proposta didática realizada em sala de aula. No entanto, a proposta do objeto foi modificada. Antes ela priorizava a promoção dos esquemas de ação e agora prioriza a coordenação dos sistemas de ação e representação simbólica por parte dos sujeitos que venham a utilizá-lo.

Não se trata de acreditamos que o Fórmula (-1), sozinho, oferece a garantia da aprendizagem das operações com números positivos e negativos. A rigor, estamos investigando a possibilidades que seu uso oferece em termos de contribuição para tais aprendizagens o que implica na continuidade da pesquisa citada nesse trabalho. Em termos de perspectiva para a continuidade desse estudo, observamos que não discutimos nesse artigo uma das relações fundamentais para o desenvolvimento do raciocínio aditivo, a relação de ordem. Tal relação será estudada via criação de outro objeto digital para a aprendizagem e que explora especificamente tais relações. No entanto, o Fórmula (-1) já se constitui em uma alternativa para o trabalho do professor e estudantes no ensino-aprendizagem das operações com números inteiros.

\section{REFERÊNCIAS BIBLIOGRÁFICAS}

CESA, Ana Cristina Possapp. Proposta de Estudo dos inteiros. UCS. p.43-47

KIMURA, Cecília F. K. TESE: Jogo como ferramenta no trabalho com números negativos: um estudo sob a perspectiva da epistemologia genética de Jean Piaget. PUC/SP, 2005.

MEDEIROS, Alexandre; MEDEIROS, Cleide. ARTIGO: Número negativos: uma história de incertezas. Bolema, Ano 7, nº , pp49 a59, 1992.

MOREIRA, Marco Antônio. A Teoria dos Campos Conceituais de Vergnaud, o Ensino de Ciências e a Pesquisa nesta Área. Investigações em Ensino de Ciências - V7(1), pp. 7-29, 2002, Disponível em: $<$ http://www.if.ufrgs.br/ienci/artigos/Artigo_ID80/v7_n1_a2002.pdf> Acesso em: 1 set. 2008.

NUNES, Terezinha. Introdução à Educação Matemática: operações numéricas. / Terezinha Nunes, Tânia M. M. Campos, Sandra Magina, Peter Bryant. - 1 ed, - São Paulo: Proem, 2001.

PIAGET, Jean, SZEMINSKA, Alina. A gênese do número na criança. Editora Zahar, Riode Janeiro, 1975.

PIAGET, Jean, INHELDER, Bärbel. Gênese das Estruturas Lógicas Elementares. Editora Zahar, Riode Janeiro, 1975.

VERGNAUD, Gérard. Atividade humana e conceituação. Editora GEEMPA, Porto Alegre, 2008.

VERGNAUD, Gérard. El niño, las matemáticas y la realidad: problemas de la ensenhanza de las matemáticas en la escuela primaria. 1ed. México: Trillas, 1991. 